\title{
Recovery of Lead and Silver from Zinc Leaching Residue Using Methanesulfonic Acid
}

\author{
Nerea Rodriguez Rodriguez, ${ }^{\dagger *}$ Bieke Onghena, ${ }^{\dagger *}$ Koen Binnemans ${ }^{\dagger}$ \\ ${ }^{\dagger}$ KU Leuven, Department of Chemistry, Celestijnenlaan 200F, P.O. box 2404, B-3001 Leuven, \\ Belgium.
}

\$ SIM vzw, Technologiepark 935,B-9052 Zwijnaarde, Belgium.

*Corresponding author:

Email: nerea.rodriguezrodriguez@ kuleuven.be

Supporting information

Total number of pages: 9

Total number of figures: 10

Total number of tables: 0 


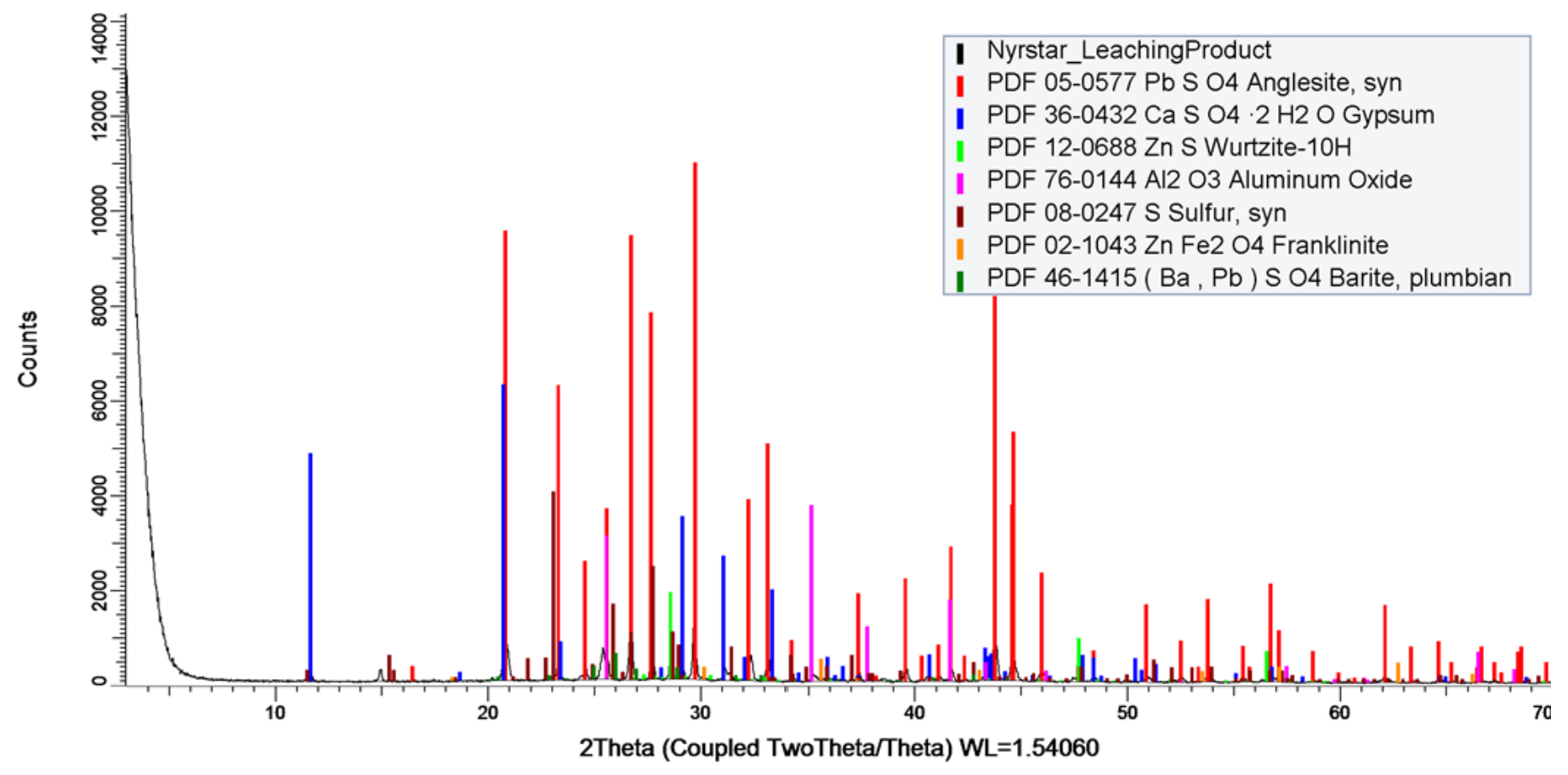

Figure S1: XRD of the dried and sieved ZLR.

\section{Randall extraction:}

In Soxhlet extraction, a volatile solvent (in this case water) is heated until evaporation in the distillation flask, and condensed back to the Soxhlet chamber, going through the solid material contained in a cellulose thimble. The condensed water is accumulated in the Soxhlet chamber to a certain level, and then the chamber is emptied and the solvent returns to the distillation flask. This process is repeated several times. In each cycle the solvent dissolves a portion of the partially soluble components (in this case gypsum), which is concentrated above its solubility (thus, re-precipitated) in the distillation flask. Soxhlet extraction is widely used in the food industry and for sample preparation in analytical chemistry. ${ }^{28}$ The use of Soxhlet 
extraction in extractive metallurgy remains unexploited, although it has been tested before for the dissolution of pure gypsum rock using water as solvent. ${ }^{29}$ Full dissolution of gypsum was achieved, but several weeks were required. In our work, a variation of the Soxhlet extraction has been considered, i.e., Randall extraction. Randall extraction could be defined as a continuous Soxhlet extraction, meaning that the condensed liquid is directly returned to the distillation flask after passing through the solid sample. Randall extraction method is much faster than conventional Soxhlet extraction.

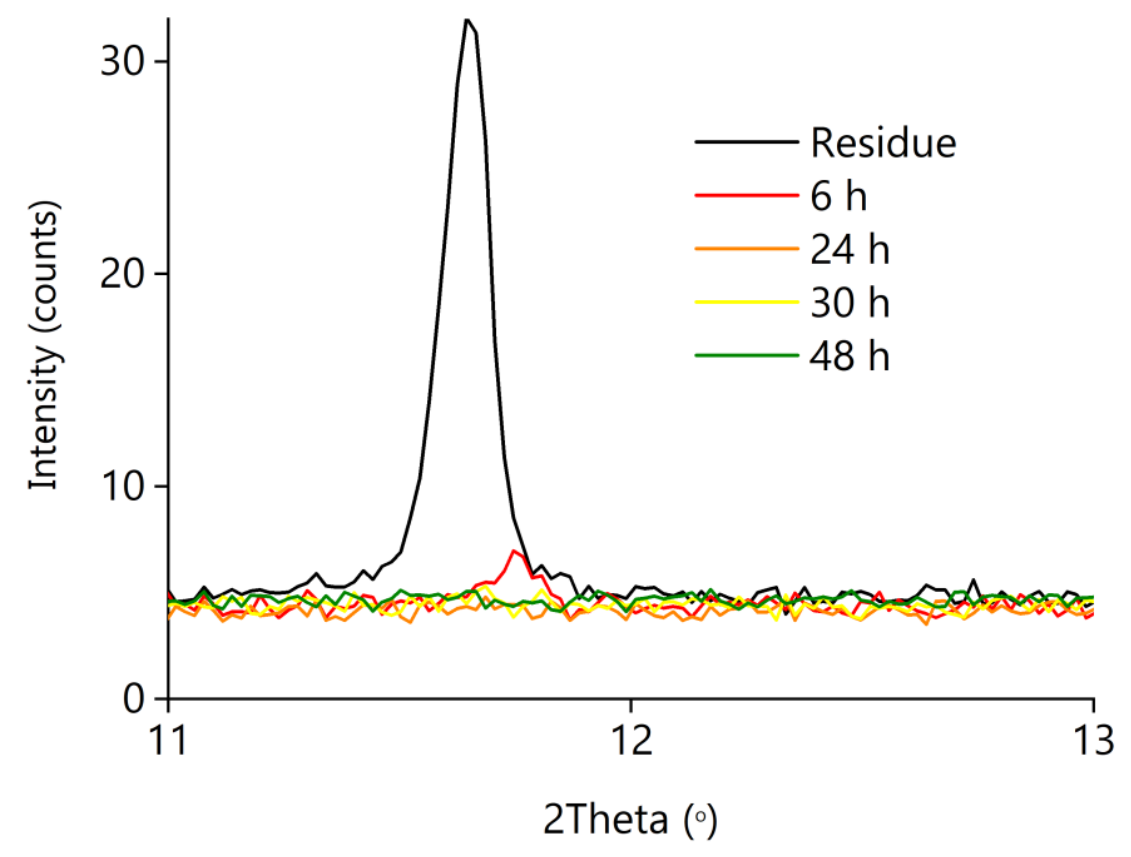

Figure S2: XRD of the dried ZLR after different Randall extraction times with water. 


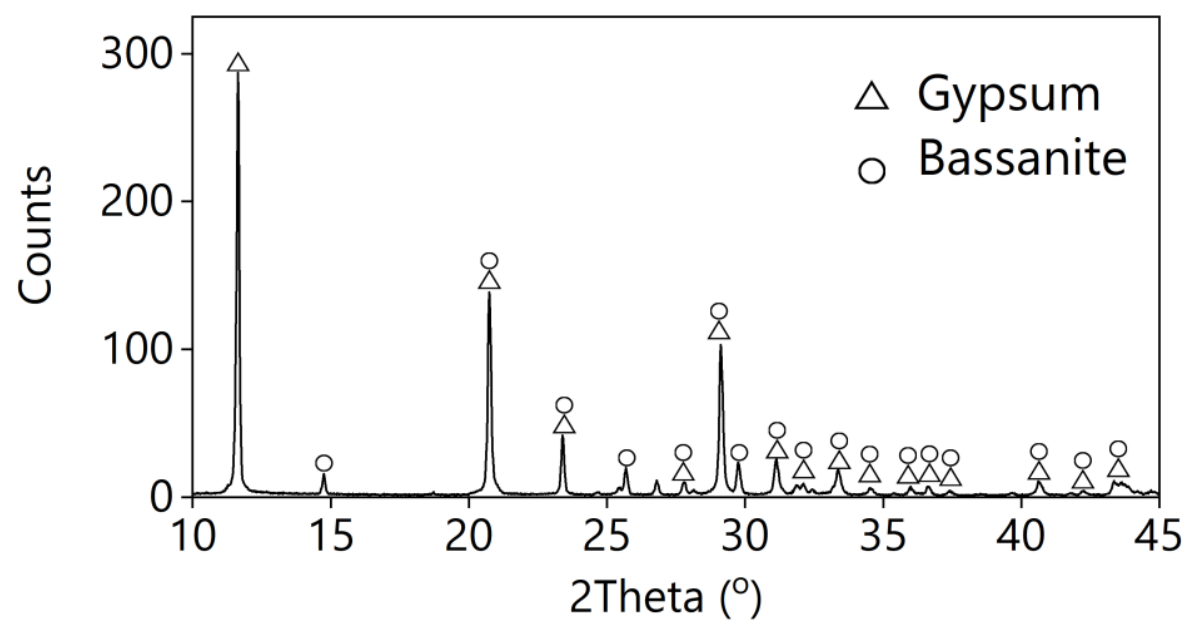

Figure S3: X-ray diffractogram of the (dried) precipitate obtained in the distillation chamber after Randall extraction.

\section{$\underline{\text { Carbonation reaction }}$}

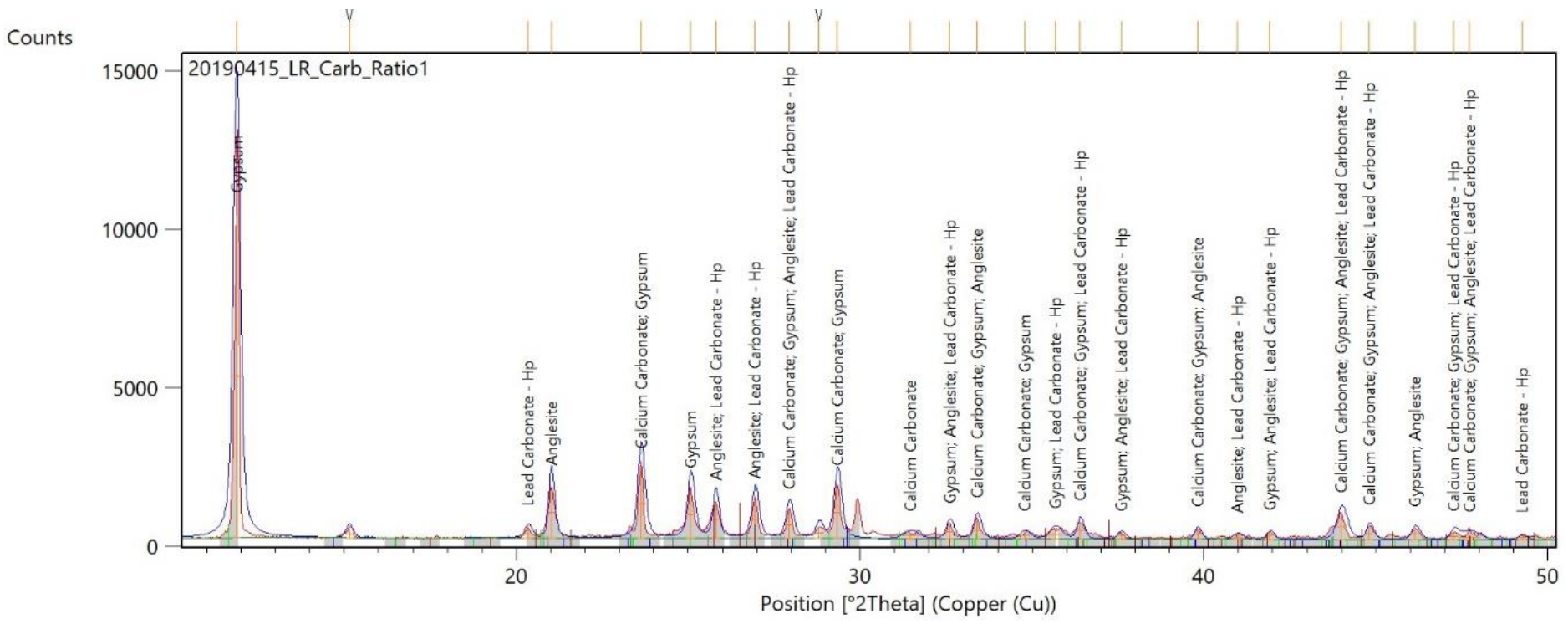

Figure S4: XRD pattern of the dried solid residue obtained after the carbonation reaction with

$$
\mathrm{CO}_{3} / \mathrm{Pb}=1 .
$$




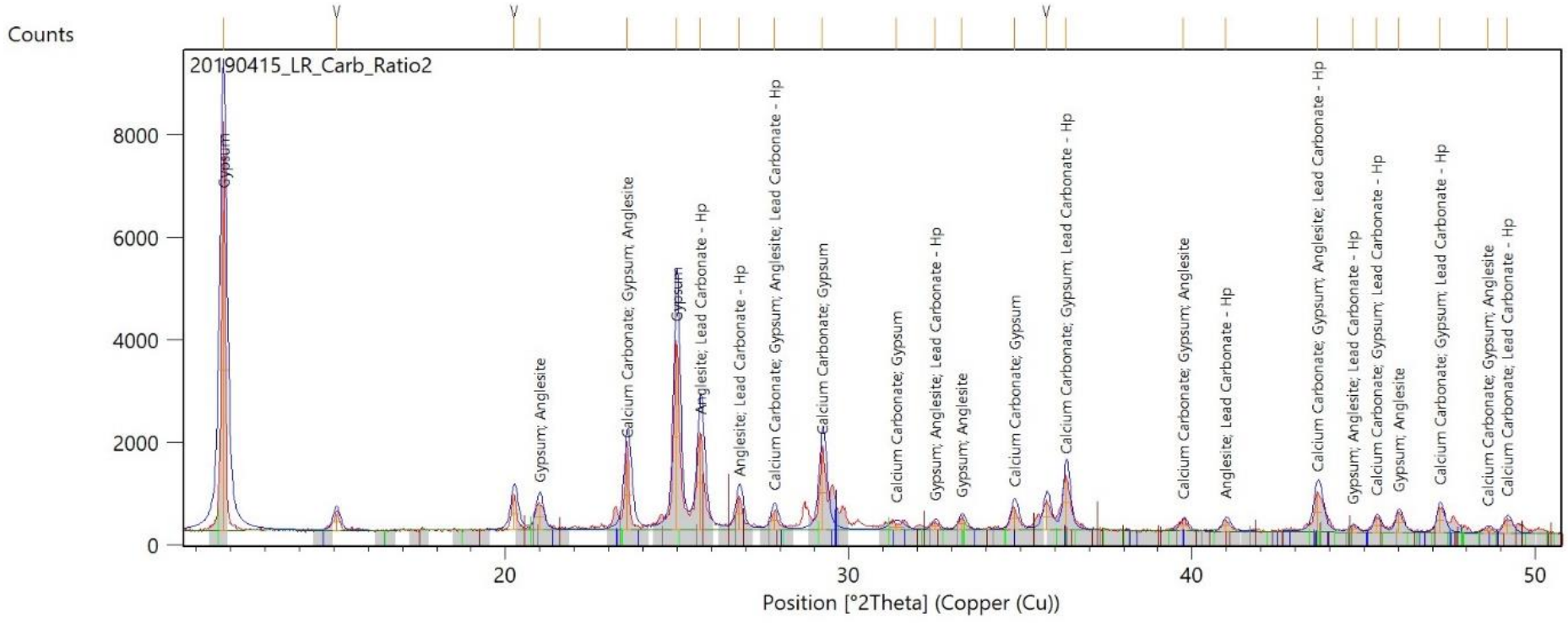

Figure S5: XRD pattern of the dried solid residue obtained after the carbonation reaction with

$$
\mathrm{CO}_{3} / \mathrm{Pb}=2 \text {. }
$$

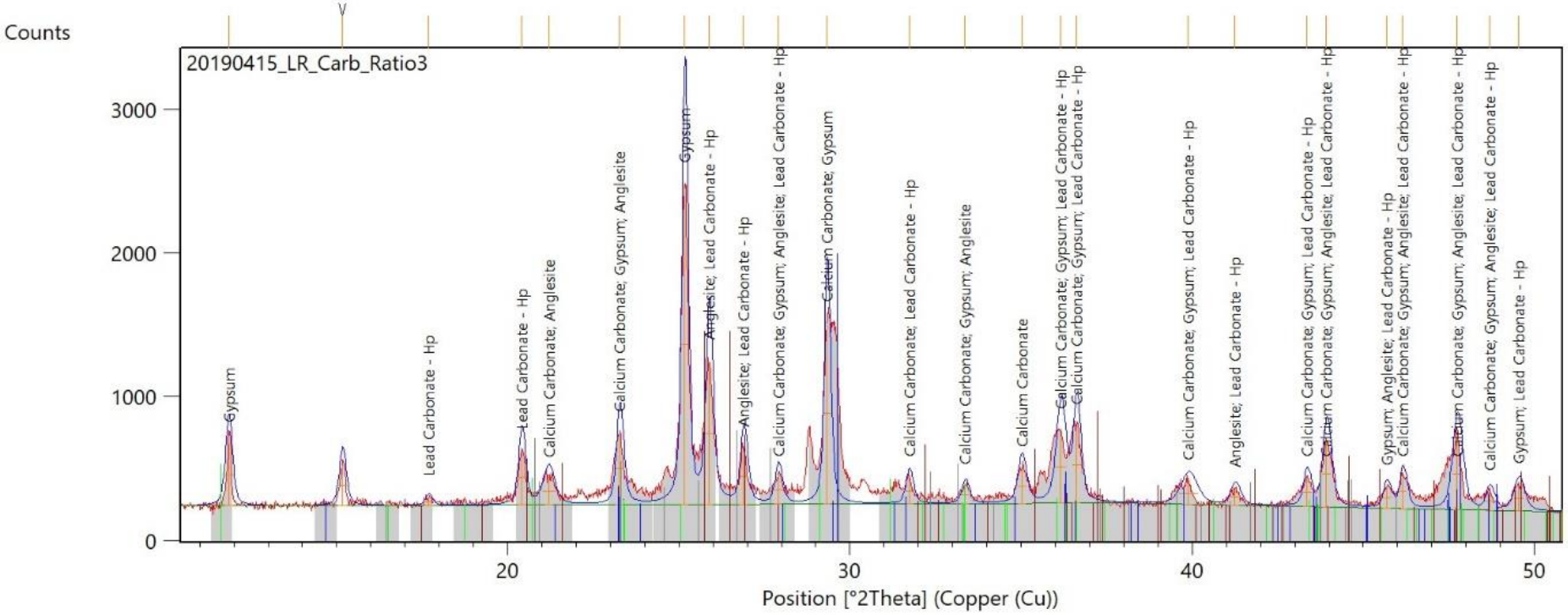

Figure S6: XRD pattern of the dried solid residue obtained after the carbonation reaction with

$$
\mathrm{CO}_{3} / \mathrm{Pb}=3 \text {. }
$$




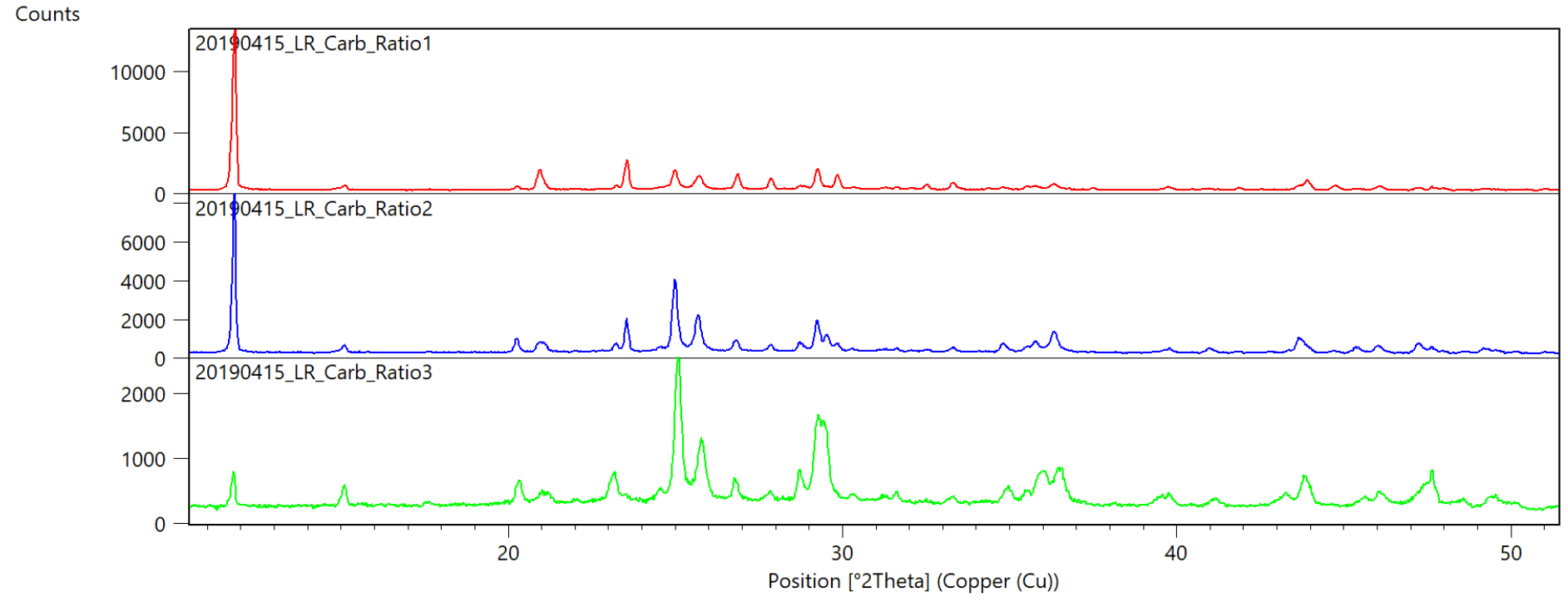

Figure S7: Comparison of the XRD patterns of the dried solid residue obtained after the carbonation of the industrial leaching residue using different $\mathrm{CO}_{3} / \mathrm{Pb}$ ratios, where red is $\mathrm{CO}_{3} / \mathrm{Pb}=1$; blue is $\mathrm{CO}_{3} / \mathrm{Pb}=2$; and green is $\mathrm{CO}_{3} / \mathrm{Pb}=3$. 
a)

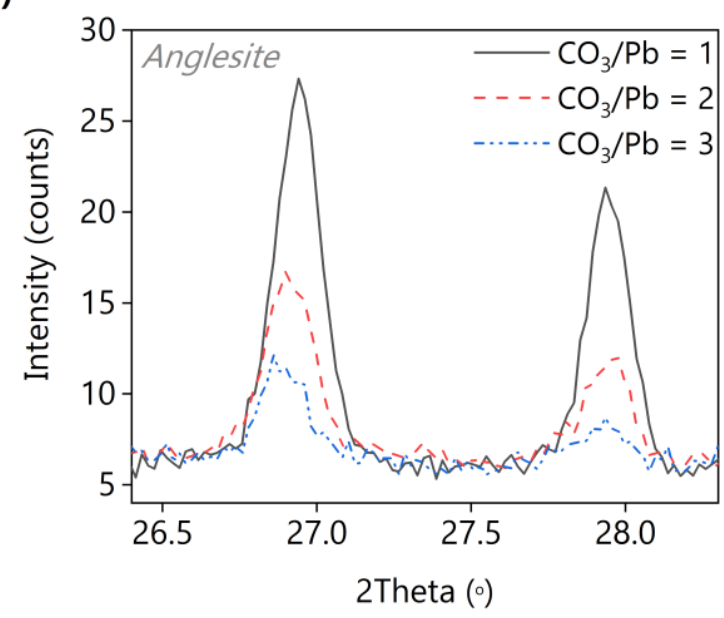

b)

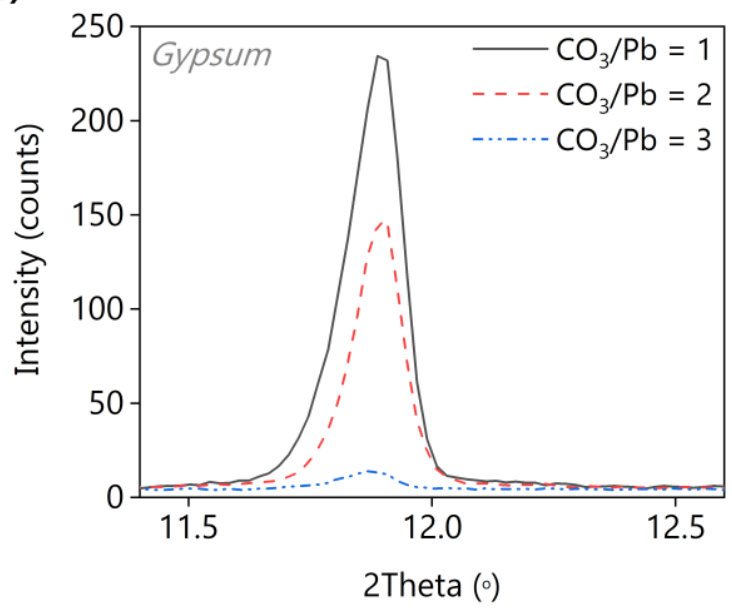

Figure S8: X-ray diffractogram of the dried solid material after the carbonation reaction. Carbonation conditions: $\mathrm{CO} 3$ source $=\mathrm{Na} 2 \mathrm{CO} ; \mathrm{T}=50^{\circ} \mathrm{C} ; \mathrm{t}=2 \mathrm{~h} ; \mathrm{L}: \mathrm{S}=10$ and MSA leaching: $\mathrm{T}=80^{\circ} \mathrm{C} ; \mathrm{t}=2 \mathrm{~h}$; $\mathrm{L}: \mathrm{S}=10$. (a) representative peak for gypsum, (b) representative peak for anglesite. 


\section{Methane sulfonic acid after carbonation reaction}

a)

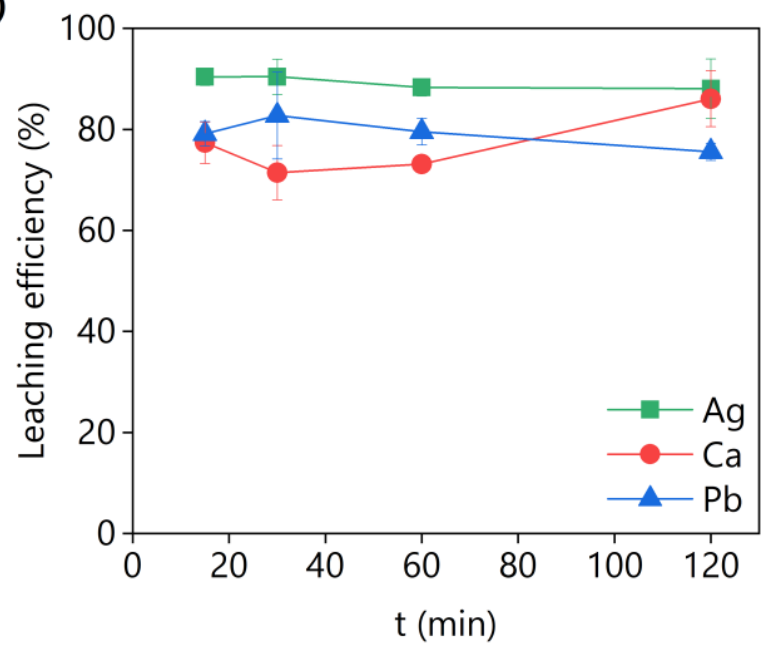

c)

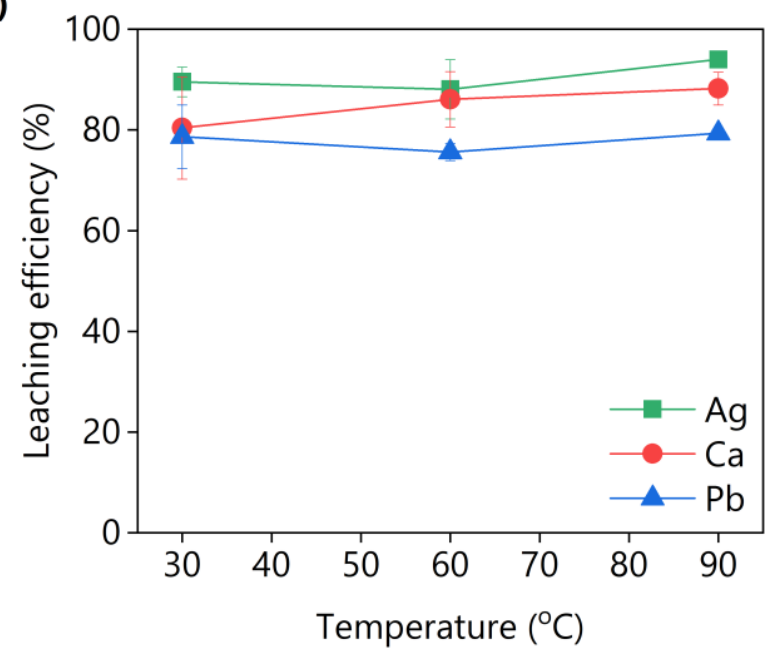

b)

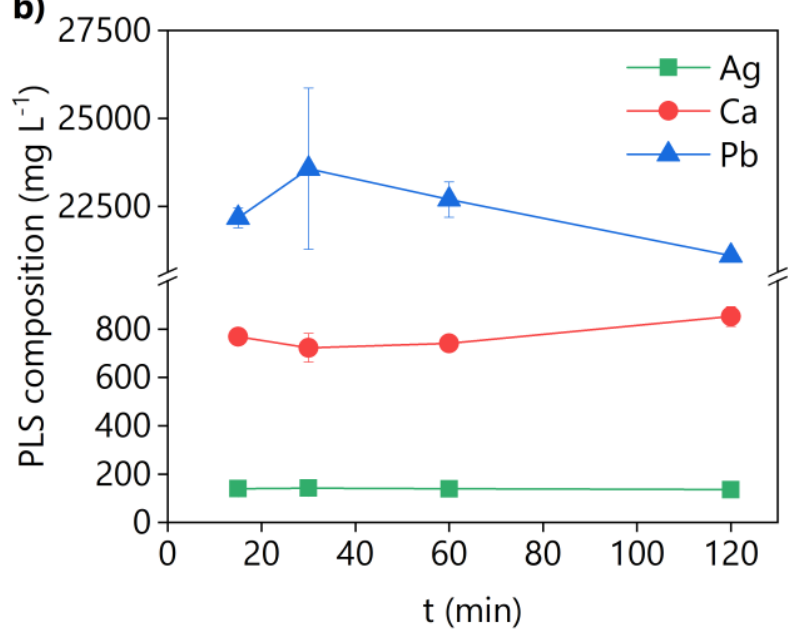

d)

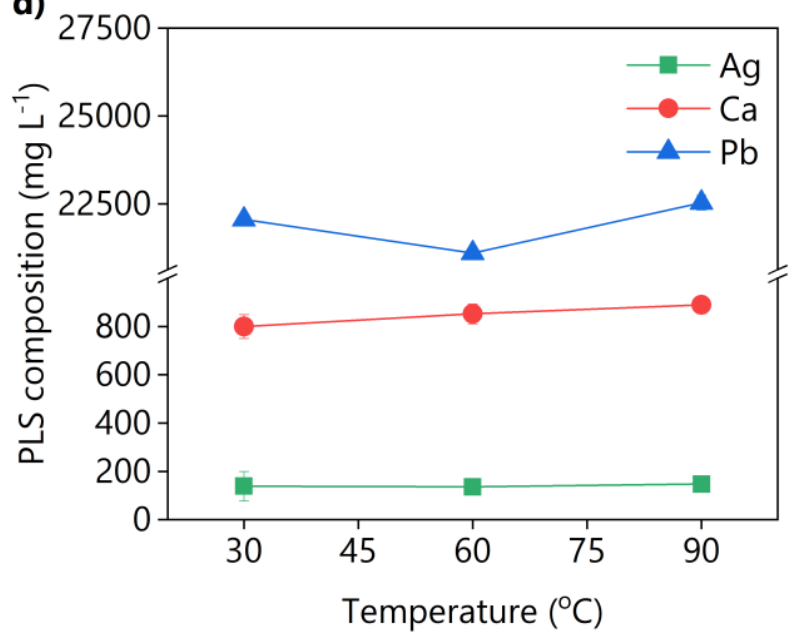

Figure S9: Effect of the carbonation reaction parameters (performed on the ZLR after $48 \mathrm{~h}$ of Randall extraction with water) on the leaching efficiency and PLS composition of the MSA leaching. $a$ and $b$ )

Carbonation conditions: $\mathrm{T}=60^{\circ} \mathrm{C} ; \mathrm{CO}_{3}: \mathrm{Pb}=2 ; \mathrm{L}: \mathrm{S}=10$ and MSA leaching conditions: $\mathrm{T}=60{ }^{\circ} \mathrm{C} ; \mathrm{t}=2$

$\mathrm{h} ; \mathrm{L}: \mathrm{S}=10$, $\mathrm{c}$ and d) Carbonation conditions: $\mathrm{CO}_{3}: \mathrm{Pb}=2 ; \mathrm{L}: \mathrm{S}=10 ; \mathrm{t}=2 \mathrm{~h}$ and MSA leaching conditions: $\mathrm{T}=60^{\circ} \mathrm{C} ; \mathrm{t}=2 \mathrm{~h} ; \mathrm{L}: \mathrm{S}=10$. 
a)

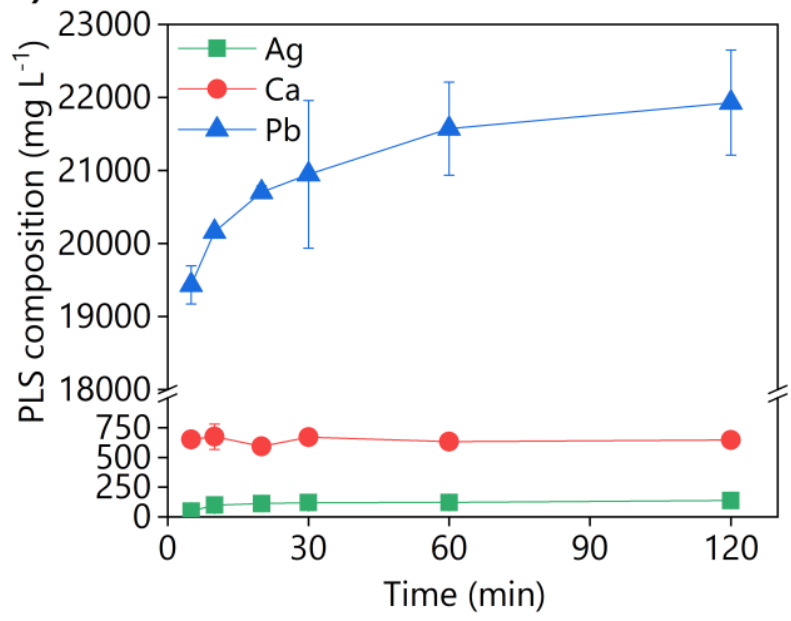

c)

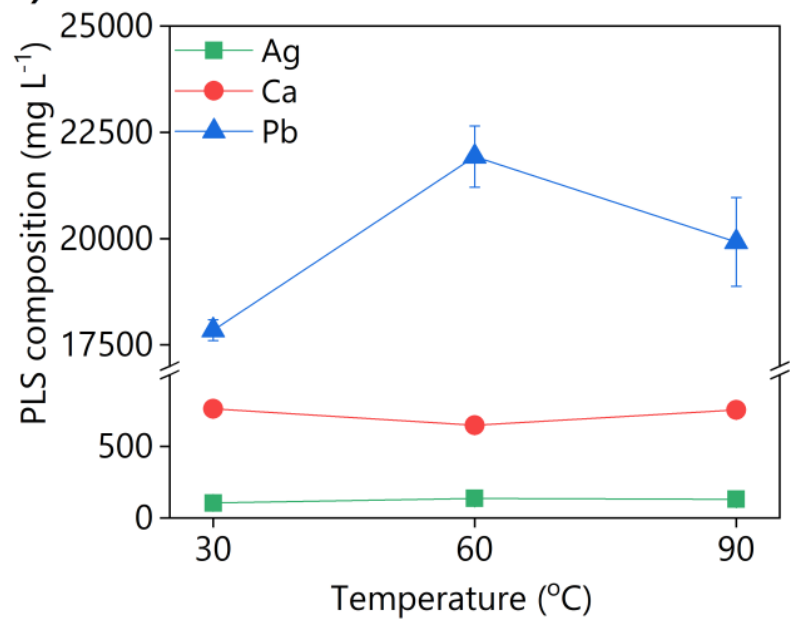

b)

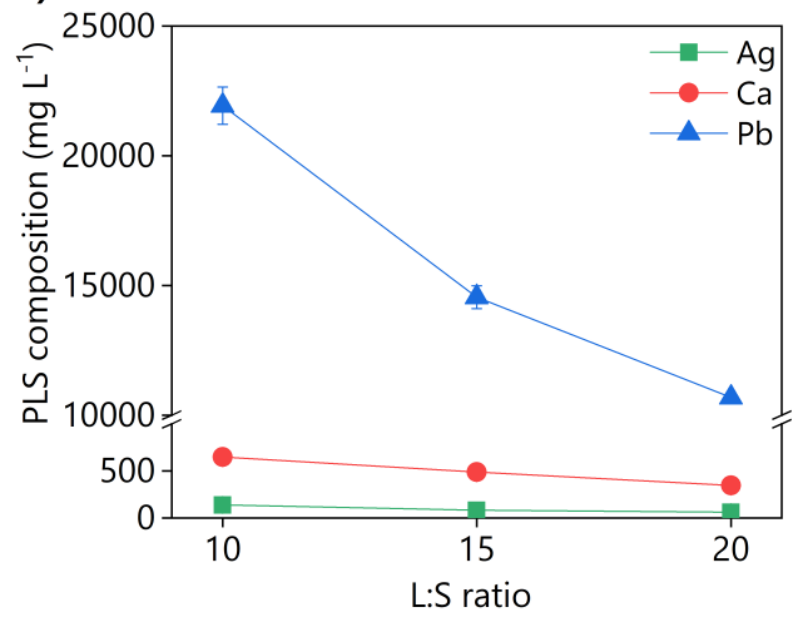

d)

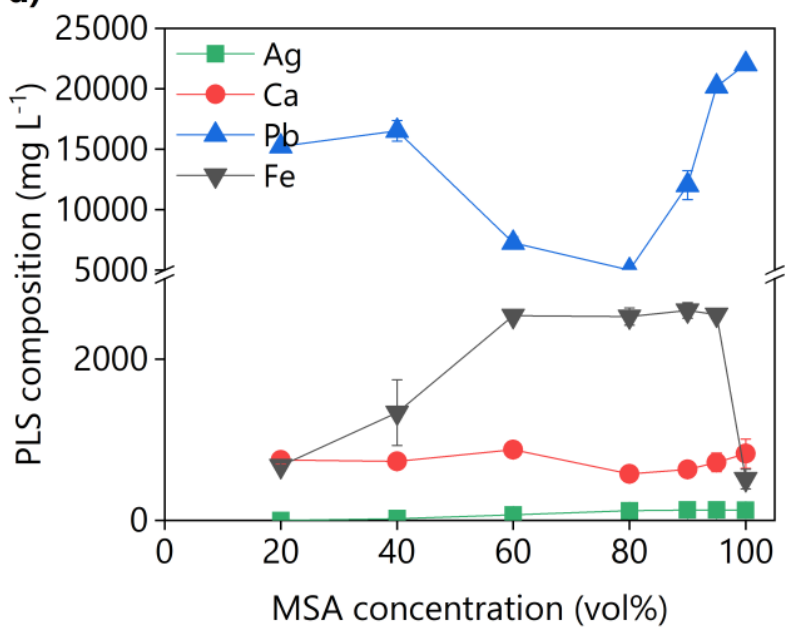

Figure S10: Effect of different leaching parameters on the composition of the PLS obtained from the MSA leaching of the pretreated ZLR. The solid material was pretreated via Randall extraction for $48 \mathrm{~h}$ using water and carbonation. Carbonation conditions: $\mathrm{CO}_{3}: \mathrm{Pb}=1 ; \mathrm{T}=60^{\circ} \mathrm{C} ; \mathrm{t}=2 \mathrm{~h} ; \mathrm{L}: \mathrm{S}=10$. Leaching conditions: a) $\left.\mathrm{T}=60^{\circ} \mathrm{C} ; \mathrm{L}: \mathrm{S}=10 ; \operatorname{MSA}(\operatorname{vol} \%)=100 ; \mathrm{b}\right) \mathrm{T}=60{ }^{\circ} \mathrm{C} ; \mathrm{t}=2 \mathrm{~h} ; \mathrm{MSA}(\operatorname{vol} \%)=$ $100 ; c) t=2 \mathrm{~h} ; \mathrm{L}: \mathrm{S}=10 ; \operatorname{MSA}(\operatorname{vol} \%)=100 ; \mathrm{d}) \mathrm{T}=60^{\circ} \mathrm{C} ; \mathrm{t}=2 \mathrm{~h} ; \mathrm{L}: \mathrm{S}=10$ 